\title{
Effect of ionic radius on the adsorption structure of various cations on 2:1 clay minerals
}

\author{
AKIKO YAMAGUCHI ${ }^{1,2 *}$, MASAHIKO OKUMURA ${ }^{1}$, \\ AND YOSHIO TAKAHASHI ${ }^{2}$ \\ ${ }^{1}$ Center of Computional Science \& E-systems, Japan Atomic \\ Energy Agency \\ (*correspondence: yamaguchi.akiko@jaea.go.jp) \\ ${ }^{2}$ Dept. of Earth and Planetary Science, Graduate School of \\ Science, The Univ. of Tokyo
}

Clay minerals, which are ubiquitous on the surface of the earth adsorb large amounts of various cations. Due to this unique property, clay minerals govern a large part of environmental behavior of various cations on the surface of the earth. For example, cesium is strongly adsorbed on clay minerals by forming an inner-sphere (IS) complex, causing its fixation on the surface of the earth [1,2]. On the other hand, rare earth elements (REE) is weakly adsorbed on clay minerals by forming outer-sphere (OS) complexes. Therefore, it is easily extracted by ammonium ions [3]. As shown above, there are different adsorption structures on clay minerals, although both of cesium and REE are hard cations. However, the origin of this difference is unclear.

The purpose of this study was to reveal the primary factor causing the difference. First, extended X-ray absorption fine structure (EXAFS) was systematically applied to various cations adsorbed on several clay minerals, including $\mathrm{K}^{+}, \mathrm{Rb}^{+}$, $\mathrm{Cs}^{+}, \mathrm{Sr}^{2+}, \mathrm{Ba}^{2+}, \mathrm{Y}^{3+}, \mathrm{La}^{3+}$, and $\mathrm{Lu}^{3+}$. We found that the cations larger and smaller than $\mathrm{Ba}^{2+}$ form IS and OS complexes, respectively. Based on this result, we made a hypothesis that ionic radius is the primary factor in determining the adsorption structure. To confirm this hypothesis, additional $\mathrm{X}$-ray diffraction and adsorption experiments were conducted. Their results were consistent with our hypothesis and suggested the specific adsorption structure of $\mathrm{Ba}^{2+}$.

Our results are useful for predicting environmental behaviors of cations for which chemical properties are unknown, such as radium $\left(\mathrm{Ra}^{2+}\right)$. Based on the systematics described above, $\mathrm{Ra}^{2+}$ is expected to form an IS complex and be fixed on clay minerals, because it has a larger ionic radius than $\mathrm{Ba}^{2+}$.

Reference: [1] Fan et al. Geochim. Cosmochim. Acta 135 (2014) 49. [2] Yamaguchi et al. J. Radioanal. Nucl. Chem. 317 (2018) 545. [3] Yamaguchi et al. Geochem. J. 52 (2018) 415. 